\title{
Articulação oracular e pesquisa de campo
}

\author{
Marcelo Moura Mello' \\ Universidade Federal da Bahia
}

Resumo: Este artigo constitui um olhar retrospectivo sobre minha pesquisa etnográfica na Guiana (antiga Guiana Inglesa) entre membros do culto à deusa hindu Kali. Analiso diversas ordens de reverberações das revelações oraculares de divindades hindus, tanto na dinâmica assumida por minha própria pesquisa como em dinâmicas rituais. Longe de me centrar em experiências subjetivas, busco refletir sobre as potencialidades trazidas por essas revelações, bem como sobre os limites conceituais de noções como crença para se compreender o culto à Kali na Guiana.

Palavras-chave: Guiana; hinduísmo; oráculos. 


\title{
Oracular articulacy and fieldwork
}

\begin{abstract}
In this article I reflect upon my ethnographic research in Guyana (formerly British Guiana), among members of the worship of the Hindu goddess Kali, through an analysis of several orders of reverberations of oracular revelations delivered by Hindu deities, both in my own research as well as in ritual dynamics. Far from focus on subjective experiences, I seek to analyse the potentialities brought by these revelations, as well as the conceptual constrains of notions as belief to understand the worship of the goddess Kali in Guyana.
\end{abstract}

Keywords: Guyana; hinduism; oracles.

\section{Articulación oracular y pesquisa de campo}

Resumen: Este artículo es una mirada retrospectiva a cerca de mi investigación etnográfica en Guyana (antigua Guyana Inglesa) entre los miembros del culto à la diosa hindú Kali. Analiso diversas ordenes de reverberaciones de revelaciones oraculares de las deidades hindúes, tanto en la dinámica asumida por mi propria investigación como en los rituales. Lejo de centrarme en experiencias subjetivas, busco reflexionar sobre los potenciales generados por estas revelaciones, así como sobre los límites conceptuales de nociones como creencia para comprender el culto a Kali en Guyana.

Palabras clave: Guyana; hinduismo; oráculos. 
$\mathrm{R}$ ecapitulações e olhares retrospectivos sobre diversas ordens de encontros na pesquisa de campo trazem consigo o potencial de forjar contornos narrativos alternativos à experiência etnográfica. ${ }^{2}$ Neste texto, longe de reconstituir em minúcias todos os meandros de minha pesquisa etnográfica realizada na Guiana - sobretudo, mas não exclusivamente, com "devotos" 3 e "devotas" da deusa hindu Kali -, busco destacar o papel de revelações oraculares de divindades hindus e de espíritos, e as reflexões de meus interlocutores a esse respeito, na própria dinâmica assumida pela minha pesquisa e nos desdobramentos das relações de membros do culto à Kali com divindades. Complementarmente, aponto as limitações de paradigmas explanatórios fundados na noção de crença no tocante às explicações normalmente avançadas acerca de oráculos e práticas divinatórias.

Considerando a proeminência assumida, em diversos estudos antropológicos sobre formações religiosas, pela subjetividade, pelo posicionamento do observador no campo e pelas distintas formas de participação de etnógrafos em rituais de caráter religioso (Cf. JOHNSON, 2016), proponho analisar mais de perto não tanto opiniões e sensibilidades subjetivas, mas antes captar mais finamente os percursos que certas instâncias de criação e recriação de relações entre humanos, divindades hindus e espíritos podem vir a assumir na pesquisa de campo e nas narrativas etnográficas produzidas a partir daí. De modo a tornar tal proposta mais inteligível, é necessário detalhar minimamente os percursos de minha pesquisa de campo, em particular os contornos assumidos por relações entre divindades e humanos em virtude de revelações oraculares que apontam menos para trajetos e caminhos pré-determinados e mais para os potenciais da circulação de pontos de vista heteróclitos em esferas rituais e não-rituais. Igualmente indispensável é apresentar elementos básicos sobre o culto à deusa hindu Kali na Guiana.

\section{Encontrando Kali}

O culto à Kali ("Kali worship", "Kali Mai Puja" ou "Madras religion”, nos termos locais) é uma vertente hindu existente na Guiana, caracterizada por uma série de práticas criadas e recriadas por descendentes de trabalhadores contratados (indentured labourers) provenientes da Índia4. Semanalmente, devotos e devotas da deusa congregam para "fazer devoção" e "fazer pujas" (ofertas, inclusive de animais) a deusas e deuses hindus, bem como para interagir com divindades que,

\footnotetext{
2 Agradeço ao apoio do Programa de Pós-Graduação em Antropologia Social do Museu Nacional, que financiou minha pesquisa de campo por meio da destinação de dotações orçamentárias da CAPES, bem como ao CNPq e à FAPERJ pela concessão de bolsas de estudos. Agradeço também à gestão da Universidade Federal da Bahia por financiar meu retorno à Guiana em 2018, por meio de edital destinado a recém-doutores (Edital 004/2016 - Apoio a Jovens Doutores PROPESQ). E agradeço a Rogério Pires e Marina França, editores e organizadores deste dossiê, pela leitura atenta e por suas sugestões para qualificar este texto.

3 Neste texto, aspas remetem a expressões, aos conceitos e a noções nativos, assim grifados apenas quando de sua primeira ocorrência.

4 O sistema de trabalho sob contrato [indentured labour] foi implementado pela Coroa Britânica e por plantadores após a emancipação, em 1834. Homens e mulheres provenientes da China, da África, de ilhas caribenhas vizinhas, da Ilha da Madeira e, principalmente, da Índia, foram recrutados para trabalhar em plantações de açúcar na então Guiana Inglesa. O recrutamento de trabalhadores da Índia se estendeu entre 1838 e 1917. Para uma análise da experiência indiana, ver: Bahadur (2013), Connoly (2019) e Look Lai (1993).
} 
ao se "manifestarem" em corpos de especialistas religiosos, conduzem tratamentos terapêuticos, transmitindo mensagens oraculares sobre as causas e origens das aflições que acometem as pessoas.

O encontro com a deusa Kali e com seus devotos e suas devotas foi suscitado por situações inesperadas, e de modo algum fazia parte de meus planos quando ingressei no Programa de Pós-Graduação em Antropologia Social (PPGAS) do Museu Nacional, Universidade Federal do Rio de Janeiro, no ano de 2009. Gozando de experiência prévia de pesquisa com comunidades remanescentes de quilombos localizadas no Brasil meridional desde 2003, decidi testar outras possibilidades de investigação no doutorado, no que fui prontamente apoiado por Lygia Sigaud, minha orientadora à época. Lygia, com seu modo caracteristicamente direto, via com bons olhos minha inclinação em não me tornar um pesquisador ultraespecializado. O curso de doutorado não só era etapa necessária de minha formação, como uma oportunidade de expandir horizontes investigativos e de imaginação.

Lygia viria a falecer, precocemente, em abril de 2009, pouco após o início do ano letivo. Após semanas angustiantes, Olívia Maria Gomes da Cunha, cuja produção intelectual já me inspirava, assumiu minha orientação, sugerindo-me a realização de uma pesquisa de campo na Guiana, uma vez que o Caribe era a região na qual seus investimentos se concentravam nos anos anteriores. Sem muita convicção, devo admitir, levei essa possibilidade adiante5, e passei a ler o (pouco) que encontrava de produção bibliográfica sobre o país. Meses depois, em janeiro de 2010, parti para a Guiana, para realizar uma pesquisa de campo exploratória por dois meses, com recursos financeiros disponibilizados pelo PPGAS ${ }^{6}$.

Pude me estabelecer na Guiana graças a Wazir Mohamed, sociólogo, historiador e professor na Universidade de Indiana, Estados Unidos. Embora só tenha encontrado Wazir na Guiana em uma única oportunidade no ano de 2012 - por ocasião do funeral de seu pai, uma importante liderança muçulmana no vilarejo onde residia -, foi com sua família que convivi nesse período inicial, pernoitando na casa de seu primo, um homem que vivia só,7 e realizando refeições na casa em frente, onde seus pais, primas, sobrinhos/as e demais parentes residiam. Com a família de Wazir iniciei o aprendizado mais efetivo das línguas ${ }^{8}$, frequentei mesquitas e participei de sessões semanais de recitação, em urdu, do Corão em âmbito doméstico, além de acompanhá-los em bares, estabelecimentos comerciais, casamentos e passeios.

\footnotetext{
5 Destaco o papel fundamental de Olívia Cunha não apenas na supervisão de minha pesquisa, mas também por sua iniciativa de propor possibilidades inovadoras de campos de pesquisa e, igualmente, de modos alternativos de se abordar problemas antropológicos.

${ }^{6}$ Inevitável referir a um contexto de relativa bonança das universidades públicas brasileiras, sobretudo em comparação com o recente projeto de aniquilação da universidade pública. Com efeito, qualquer consideração sobre pesquisas empíricas deve levar em conta condições de possibilidade historicamente contingentes e mutáveis.

7 Durante a maior parte da minha pesquisa, diversas famílias indo-guianenses manifestaram reservas em me hospedar, em especial em residências onde jovens solteiras residiam. Minhas interações se deram sobretudo, mas não exclusivamente, com homens jovens e de meia-idade. Em relação às mulheres, boa parte de minhas interações se deu em espaços públicos, ou em companhia de seus familiares. Com idosas e crianças meu contato era mais facilitado.

Sinah Kloß, antropóloga alemã que realizou sua pesquisa de campo quase que concomitantemente à minha, apresenta diversas reflexões sobre os constrangimentos, imposições e violências enfrentados por antropólogas em campo, atentando para as dinâmicas de relações de gênero na Guiana (KLOß, 2017).

8 A língua oficial da Guiana é o inglês britânico. Na prática, guianenses alternam suas falas entre versões mais próximas do inglês padrão e diversas modulações do creolese, língua crioula do país (BICKERTON, 1975; RICKFORD, 1987; SIDNELL, 2005). Dediquei maior atenção à questão da língua alhures (MELLO, 2014: 26-41). Minhas conversações foram entabuladas, normalmente, em inglês, embora progressivamente tenha me familiarizado com as diversas modulações e variações do creolese. Em relação a outras línguas - urdu, árabe, tâmil e híndi - meu aprendizado se limitou, tão somente, ao aprendizado de algumas dezenas de palavras, em especial aquelas empregadas nos domínios das relações de parentesco, do ritual e da religião, da culinária e de plantas.
} 
Meu projeto de pesquisa inicial, tão provisório quanto precário, propunha-se a estudar comerciantes de artigos religiosos de origem indiana. Tal projeto se definiu, em larga medida, pelas orientações de Olívia Cunha, que me alertara para o fato de a população indo-caribenha ter sido relativamente negligenciada pela produção caribeanista, bem como para o privilégio conferido pela diminuta bibliografia sobre a Guiana a questões relativas à raça e à etnicidade, algo decorrente das instabilidades e dos conflitos persistentes entre os dois maiores segmentos populacionais do país, os indo-guianenses e os afro-guianenses. 9 Olívia não só me estimulou a testar outras teorias etnográficas, como sugeriu que no âmbito religioso as diferenças étnico-raciais da Guiana poderiam se configurar de modos inesperados.

Assim, ao chegar na Guiana apresentei-me como um estudante de antropologia interessado em aprender mais sobre a vida religiosa no país. $O$ fato de eu ser brasileiro surpreendia um tanto, pois além de eu não me assemelhar a "brazus", parecia peculiar às pessoas com quem interagi o fato de um brasileiro realizar estudos na Guiana. ${ }^{10}$ Ao revelar meus planos a meus anfitriões, passei a ser conhecido como um sujeito interessado em estudar "religião", assim definida em termos amplos. Meus anfitriões faziam referências constantes à vida religiosa no país, em especial ao islamismo, pois eram muçulmanos. Concomitantemente, assuntos correlatos ganharam proeminência. Desde meu primeiro dia em campo, de fato, menções a "jumbies" (espíritos de mortos) e à feitiçaria surgiram quase que espontaneamente.

Evidentemente, havia uma razão para isso. Ouvi falar não só de diversos casos de ataques espirituais e/ou de feiticeiros, amplamente noticiados em jornais e em telejornais, aliás, como descobri, logo a seguir, que a casa onde eu vivia era considerada mal-assombrada, restando em uma área onde existiu uma plantação de cana-de-açúcar no passado - e, portanto, servido de morada de espíritos de colonizadores. ${ }^{11}$ Progressivamente passei a fazer indagações mais detalhadas a respeito desses tópicos, sempre tomando o cuidado de não direcionar excessivamente o rumo das conversações. Invariavelmente, meus interlocutores e interlocutoras recomendavam-me "procurar o povo de Kali" caso eu quisesse saber mais a respeito, pois eram eles que "lidavam", e "sabiam como lidar", com "esse tipo de coisa”.

A dada altura, por meio da intermediação, à distância, de Wazir, encontreime com Swami Aksharananda, diretor de uma escola privada hindu, doutor em

\footnotetext{
9 O processo de independência da Guiana, concretizado em 1966, deixou profundas fraturas na sociedade guianense, pois o principal partido independentista cingiu ainda na década de 1950, dando surgimento a dois partidos, um apoiado quase que exclusivamente por indo-guianeses e outro por afro-guianeses. Adicionalmente, diversos conflitos tiveram lugar entre esses grupos, antes, durante e após a independência (ver HINTZEN, 1989 e SMITH, 1995). Para uma reveladora análise, remeto à fascinante etnografia de Williams (1991). Ver também: Pires, Strange e Mello (2018).

1o Raríssimas vezes fui identificado como brasileiro na Guiana, que são popularmente chamados de "brazus". Para os/as guianenses eu não me assemelhava, fisicamente, a outros brasileiros, em sua maioria garimpeiros. Provavelmente, hábitos encorporados pela minha circulação em espaços sociais intelectualizados e privilegiados no Brasil refletiram-se em posturas corporais idiossincráticas. Em geral, eu era identificado como americano, muito em virtude de meu cabelo, e, em menor medida, como norte-indiano, em especial por afro-guianenses. Em termos de categorias de cor, eu era classificado como "mixed", alguém que certamente não era indiano, nem africano, nem branco (identificação restrita a descendentes de norte-europeus). Considero que o fato de eu ser brasileiro, em si, não foi tão relevante para minha inserção em campo. Certamente, em algumas situações meu espírito "amigável" era contrastado ao de europeus e americanos, pessoas em geral brancas e com pendor, para meus interlocutores, a inferiorizarem guianenses. De todo modo, e apesar da presença de milhares de brasileiros e brasileiras na Guiana, sobretudo em áreas de garimpo, meus interlocutores tinham pouco contato com pessoas do Brasil. Por fim, um último comentário. O fato de eu ser brasileiro, e não-branco (nos termos locais), dificultou minha inserção em círculos intelectuais. Pode bem ser que se trate de uma percepção pessoal equivocada, mas a minha origem não metropolitana era algo que parecia importar para alguns intelectuais e para pessoas com alguma posse.

${ }^{11}$ Isto é, espíritos de colonizadores holandeses, cujas moradas são, normalmente, áreas onde existiriam, no passado, plantações de açúcar. Para mais detalhes, ver Mello (2020) e o instigante artigo de Williams (1990). Espíritos holandeses são considerados, para os moradores da região da costeira da Guiana, como os "donos da terra", detendo prerrogativas e direitos sobre certos locais.
} 
filosofia pela Universidade de Madison, Estados Unidos. Ao saber de meu interesse no "povo de Kali", Aksharananda recomendou-me ir a Berbice, região localizada a mais de cem quilômetros de onde eu morava, na costa ocidental de Demerara ${ }^{12}$, pois era ali que eu encontraria, em seus termos, os templos "mais tradicionais". No mesmo dia, Aksharananda me pôs em contato com um amigo seu, residente em Berbice, com quem me encontrei pessoalmente dias depois. Esse senhor, Rudy, que era indiano e hindu, me levou a um templo de Kali, apesar de sua profunda aversão ao que "aquelas pessoas" faziam, como sacrifícios de animais. Em sua visão, o povo de Kali “deturpava” princípios centrais do hinduísmo, e o culto à Kali não era propriamente uma religião, mas antes um "culto selvagem”. Seja como for, não só fui muito bem recebido por Rudy e sua família, como passei a frequentar o templo de Blairmont, todos os finais de semana.

A chegada a Blairmont também não foi planejada, pois Rudy não tinha um plano em mente quando me conduziu até o local, não sem antes fazer questão de percorrer comigo o vilarejo negro vizinho de Ithaca, para eu ver, com os próprios olhos, como os "negros viviam" (Rudy deplorou, particularmente, a aparente falta de disposição desses em cuidarem de seus quintais). Durante essa jornada, Rudy comentou que já ouvira falar de um sacerdote de Kali que vivia próximo à sua residência, levou-me ao vilarejo onde este morava, e indagou passantes. Em um bar, descobrimos que tal sacerdote viajara para as Ilhas Virgens Americanas apenas dois dias antes. Entretanto, encontramos seu filho, Vijay, que sugeriu, efusivamente, que fôssemos ao templo de Blairmont. Ao chegar em Blairmont, Vijay não se encontrava lá, apenas a chefe da cozinha do local, Nadya, e alguns meninos e meninas, que me convidaram para pernoitar ali e conversar com o sacerdote no dia seguinte ${ }^{13}$.

Após esse primeiro contato - na metade final de meu campo exploratório, portanto - decidi reorientar minha pesquisa, enfocando o culto à Kali. Tal resolução se pautou tanto pela excelente recepção das pessoas quanto pelo fascínio que os rituais exerceram em mim, fascínio esse estimulado menos por exotismo - fator certamente relevante e que explica, em alguma medida, a proeminência de estudos sobre essa vertente hindu na Guiana, em detrimento de outras, como notou Kloß (2016) - e mais pelas sensações despertadas pela profusão de cores, cheiros, aromas, sons e de movimentos de artefatos rituais e de corpos. Diante desses estímulos sensoriais, seria possível agregar à descrição etnográfica o potencial daquilo que Michael Taussig (2009) chamou de "conscientização do corpo do investigador no entendimento da abrangência do mundo", na medida em que os encontros e os contatos com o universo de Kali permitiriam explorar as potencialidades de um "conhecimento sensual” (Cf. STOLLER, 1997), relativizando a ênfase visualista da disciplina em prol da construção de relações de conhecimento atentas às limitações de oposições rígidas entre visual e textual, corporal e mental, material e imaterial.

Outro fator foi relevante, qual seja: a maior abertura, por assim dizer, dos templos de Kali a indivíduos vinculados a outras formações religiosas e a afroguianenses, algo bastante diferente do que sucede na vertente hindu preponderante na Guiana, o Sanatan Dharma. Não é que meus interlocutores e minhas interlocutoras, majoritariamente de origem indiana, não possuíssem rivalidades

\footnotetext{
12 Não disponho de espaço para abordar em detalhes aspectos relativos à geografia e à topografia da Guiana, um país situado abaixo do nível do mar e no qual $96 \%$ da população reside em uma estreita faixa territorial costeira que compraz cerca de $4 \%$ da área total do país. O deslocamento entre as três regiões da Guiana - Essequibo, Demerara e Berbice - é um tanto dificultoso, mesmo que as distâncias entre os locais (do ponto de vista de brasileiros) pareça curta.

${ }_{13}$ Coincidentemente, ou não, Vijay não quis nos acompanhar, vim a descobrir após algumas semanas, porque seu pai, o sacerdote que procurávamos, havia cortado relações com o templo de Blairmont.
} 
com afro-guianenses, nem que se furtassem de fazer comentários estereotipados sobre estes. Contudo, efetivamente assiste-se à participação de pessoas de diversas origens no culto à Kali, muitas das quais sem vínculo prévio com essa vertente religiosa $^{14}$ (voltarei a isso, destacando o papel de revelações oraculares em dinâmicas de pertencimento religioso).

Devo mencionar que os conflitos entre afro-guianenses e indo-guianenses, documentados em todas as obras que consultei previamente à minha pesquisa de campo, gerou-me certas hesitações, na medida em que minhas convicções e meu compromisso pessoal, ético e político com comunidades remanescentes de quilombos no Brasil seria colocado à prova em um país no qual fraturas motivadas por rivalidades entre dois grupos subalternos não só geraram animosidades persistentes como violentos embates, inclusive no passado recente (ver TROTZ, 2004). Como Olívia Cunha me sugerira, realizar pesquisa de campo na Guiana era desafiador, pois seria necessário não reduzir toda a vida de guianenses à raça/etnicidade e, em paralelo, ter disposição para compreender em outros termos linguagens que fazem referência à raça/etnicidade.

Iniciada minha pesquisa sobre o culto à Kali, decidi concentrar minhas observações em um templo apenas, Blairmont, pois julgava que assim poderia me aproximar melhor das pessoas, além de prevenir embaraços resultantes de faccionalismos internos. ${ }^{15}$ Estava, e permaneço, totalmente ciente de que tal escolha limita generalizações sobre o culto à Kali como um todo na Guiana. Afinal de contas, e como dizem meus interlocutores, "cada templo faz as coisas do seu modo". Precisamente por isso, descrições etnográficas localizadas me parecem mais rentáveis, até porque proporcionam acompanhar mais de perto como as relações das pessoas com o culto à Kali se desdobram no tempo, inclusive por meio de conflitos, cisões, distanciamentos e rupturas - ponto finamente captado por Rabelo (2014) em seu estudo sobre o candomblé na Bahia.

Findo o campo exploratório, regressei ao Brasil em abril de 2010, planejando uma nova e longa viagem para o segundo semestre daquele ano. Em virtude de demandas burocráticas ${ }^{16}$, reajustei meu cronograma: em vez de realizar um campo ininterrupto de nove meses, como inicialmente previa, realizei mais três viagens a Guiana, que totalizaram mais oito meses de pesquisa de campo. Na segunda etapa da pesquisa residi, por algumas semanas, em Georgetown, capital do país, onde realizei diversas incursões em bibliotecas, encontrei intelectuais locais e consolidei relações com algumas pessoas, de diversas origens e filiações religiosas. Em fevereiro de 2011, passei duas semanas seguidas no interior do templo de Blairmont, acompanhado os preparativos do principal festival religioso do calendário anual do culto à Kali, o "Big Puja”.

Nesse período, minha esposa, Marcela, que me visitava durante seu período de férias letivas, acompanhou-me em diversas incursões etnográficas. No último dia do festival, em virtude de uma sugestão do sacerdote do templo, Bayo, nossa união foi celebrada pela deusa Mariamma em uma cerimônia religiosa17. Esse momento foi considerado por meus interlocutores como um evidente sinal de nossa

\footnotetext{
14 De resto, confesso que nunca nutri muita simpatia por grandes religiões; interessava-me mais por práticas minoritárias. 15 Estima-se que existam mais de 100 templos de Kali na Guiana. A circulação de pessoas entre vários templos é comum. Durante a etapa final de minha pesquisa houve uma cisão no templo onde eu concentrava minhas observações, o que resultou no deslocamento de vários de seus membros para outro templo, que se tornou rival a aquele.

16 Fui obrigado a retornar ao Brasil, após viajar para a Guiana novamente em novembro de 2010, em março de 2011, devido à concessão de uma bolsa de pesquisa da Fundação de Amparo à Pesquisa do Estado do Rio de Janeiro (FAPERJ). As assinaturas dos termos de concessão e de outorga da bolsa demandavam minha presença física no Brasil.

17 As implicações da presença de minha esposa em meu campo, e de nosso casamento, não serão objeto de reflexão aqui (ver MELLO, 2014: 198-208). Chamo a atenção para o fato de dezenas de pessoas - que, ao menos inicialmente, não sabiam dos meus propósitos antropológicos - atribuírem minha estada ali a algum problema de infertilidade, pois parecia-
} 
disposição em conviver com as pessoas. Adicionalmente, atestou uma inclinação verdadeira de minha parte em efetivamente me tornar alguém "próximo da religião", e não somente um visitante, afinal eu regressaria ao local no futuro desacompanhado de minha esposa, mas com vínculos já estabelecidos, inclusive com Marcela, com o templo, com as divindades e com seus membros.

O culto à Kali não é para espectadores, e esse é outro aspecto importante a ser mencionado. Desde meus primeiros encontros com Kali minha inclinação de não tomar notas na frente de meus interlocutores reforçou-se devido à impossibilidade de ser um mero observador, distante e alheio às tarefas realizadas no templo. Além de seguir a "abstinência" requerida para frequentar os templos ${ }^{18}$, fui instado a auxiliar os membros de Blairmont em tarefas práticas, além de acompanhar as pessoas fora do templo ${ }^{19}$ e em atividades de lazer. Como comentou diversas vezes o sacerdote Bayo, para aprender sobre "a religião", eu deveria "viver como um devoto", algo que implica envolvimento com os preparativos dos rituais - colher flores, regar árvores, varrer e esfregar o chão.

Outra inflexão fundamental de minha pesquisa se deu na terceira viagem realizada à Guiana em setembro de 2011, quando não só passei a residir com um jovem muito assíduo em Blairmont, Omar, como assumi um novo papel nas dinâmicas rituais de Blairmont, muito em virtude de uma revelação oracular da deusa Mariamma, que se manifestava no sacerdote Bayo: eu deveria realizar, por nove semanas, "devoção" para algumas divindades, em prol do bem-estar físico de uma parente próxima, que se encontrava, então, adoentada. Tal prescrição, suscitada por uma revelação oracular da deusa, apesar de bastante inesperada para mim, mas não para Bayo, que sabia previamente da condição de saúde de minha parente, é consoante à maneira pela qual as pessoas estabelecem, criam e recriam relações com as divindades. De modo a tornar isso mais evidente, é necessário tecer algumas considerações sobre o papel das mensagens oraculares divinas na criação e recriação de relações entre membros e divindades de Blairmont.

\section{Articulação oracular}

Nos cerimoniais do culto à Kali que ocorrem semanalmente, o momento mais aguardado por devotos e devotas é a invocação de divindades nos corpos de especialistas religiosos, "marlos", cujos corpos se tornam temporariamente veículos da agência divina. Ao serem invocados, deuses e deusas conduzem tratamentos terapêuticos, prescrevem a realização de práticas de devoção por determinado período de tempo e "revelam" as causas e os motivos das "aflições”, das "doenças" e dos "problemas" que se abatem sobre as pessoas. Marlos são homens e mulheres cujo treinamento para manifestar divindades já se encontra consolidado. Resumidamente, por meio de uma série de manipulações rituais e da preparação do corpo e da mente desses especialistas religiosos, o poder divino ("shakti") infunde-se nestes/as, disseminando-se entre as demais pessoas, sobretudo por meio das ações performadas durante a manifestação.

\footnotetext{
lhes estranho que Marcela e eu não tivéssemos filhos. Essa percepção se explica também pelo fato de diversos casais buscarem o auxílio das divindades hindus para gerar um rebento.

${ }_{18}$ Os rituais semanais de Kali ocorrem aos domingos. Na sexta-feira anterior, pessoas que pretendem frequentar o templo devem iniciar a abstinência, evitando o consumo de fibra animal, álcool e entorpecentes, além de evitar qualquer ordem de contato sexual, consigo mesmo ou com outras pessoas.

${ }_{19}$ Com efeito, aprendi muito sobre o culto à Kali fora do templo, "gaffing" (conversando descompromissada) com membros do templo em outros espaços, como bares.
} 
Em um estimulante e recente artigo, Anastasios Panagiotopoulos (2018) analisa a troca, a circulação e os comentários suscitados por conhecimentos, mensagens e narrativas expressas por meio de revelações oraculares entre adeptos de religiões afro-cubanas. Panagiotopoulos demonstra, muito habilmente, como "redes oraculares" se tornam significantes pontos de referência não só no domínio religioso, como na vida diária de afro-cubanos, de modo que os pronunciamentos oraculares não só constituem pontos de atração para as pessoas como abrem caminhos múltiplos e cruzados, caminhos esses que tornam "a divinação um significante ponto de referência e de ação" (PANAGIOTOPOULOS, 2018: 478). Segundo o autor, articulações oraculares se constituem em pontos de partida, de passagem e de entrecruzamento de diversos pontos de vista. Pronunciamentos oraculares são levados a sério não tanto pela tenacidade de crenças religiosas, mas antes porque revelações oraculares podem transformar os próprios caminhos das pessoas, além de portarem consigo o potencial de apresentar novos elementos sobre acontecimentos do passado, do presente e do porvir.

As sugestões de Panagiotopoulos parecem-me produtivas por uma série de motivos, como espero deixar evidente abaixo. A título de ilustração, noto que diversos membros de Blairmont não eram, como se diz, "nascidos na religião", ou seja, não tinham vínculo prévio com o culto à Kali. Em comum à trajetória de várias pessoas é a importância que revelações oraculares assumiram em suas vidas e em seus pertencimentos religiosos. Dezenas de homens e mulheres eram hindus de outras vertentes, muçulmanos, cristãos e mesmo sem religião, até que algum acontecimento inesperado, como o surgimento de doenças cujas origens nem médicos conseguiam determinar, impeliu as pessoas a frequentar um templo de Kali, onde não raro se "curaram" após deuses e deusas determinarem as origens e a causas de seus problemas. Tais revelações atestavam não só o poder das divindades, mas também a "veracidade" dos atos performados por meio de marlos, e a própria qualidade da devoção destes últimos.

Idealmente, marlos não detêm qualquer lembrança dos eventos que sucedem durante a manifestação, pois perdem sua consciência quando manifestam as divindades, tornando-se veículos de fala e de ação de seres com estatuto ontológico distinto dos humanos, as divindades. Entretanto, não só se admite francamente a possibilidade de se "forjar" uma manifestação (MELLO, 2020), como se sugere que diversos fatores podem "interferir" na "profundidade" da manifestação. Ou seja, se as manifestações sempre se efetuam em determinados "níveis" (mais ou menos "profundas", "plenas" ou "puras"). Assim, pode bem ser que uma influência maligna (de espíritos ou de feitiços, por exemplo), ou que a instabilidade corporal e emocional de uma pessoa, faça emergir relances da consciência individual de marlos, que, ademais, muitas vezes detêm um conhecimento prévio da vida dos consulentes. Não à toa, ressaltaram diversas vezes meus interlocutores e interlocutoras, a melhor maneira de se certificar da "seriedade" de um templo de Kali desconhecido é não revelar a ninguém as motivações de se estar presente ali. Se o templo em questão é sério, se diz, "as divindades farão o seu trabalho e descobrirão o que realmente se passa”.

As mensagens oraculares no culto à Kali remetem à "verdade", pois têm origem extra-humana, provindo de seres "poderosos" e "puros". Contudo, não há garantia absoluta de que uma mensagem comunicada por uma divindade seja totalmente precisa. Para se ter garantias a esse respeito, é necessário, primeiramente, que o treinamento, como dito, esteja consolidado, e que marlos mantenham a "constância" da sua devoção - isto é, foquem os pensamentos nas divindades, rezem diariamente para elas, realizem ofertas continuamente, sigam à 
risca a abstinência e previnam a emergência de influências malignas em seus corpos. Em segundo lugar, "testes" são realizados no próprio ato da invocação, testes esses que incidem sobre os corpos de marlos, seja por meio de açoitamentos com cordas molhadas em seus braços e pernas, seja pela ingestão temporária de cubos de vela acesos em suas bocas. Esses atos certificam a ocorrência de manifestações divinas, pois seres malignos e indivíduos conscientes não escapariam imunes a tais regimes de provação corporal.

Acompanhei uma série de situações nas quais as revelações das divindades ditaram cursos de ação, reconfiguraram relações e (re)ordenaram arranjos prévios. Esse foi o caso, por exemplo, de uma jovem que, repleta de dúvidas quanto às reais intenções de seu noivo, decidiu levar adiante seu casamento após uma divindade (manifestada coincidentemente, em seu pai) assim o recomendar. Foi também o caso do jovem ansioso por migrar para os Estados Unidos que protelou o pedido de visto junto à Embaixada Americana, de modo a lograr sucesso; bem como de uma divindade que espancou um homem que, aparentemente, manifestava o deus Khal Bhairo, quando em realidade tal sujeito "se passava" pela divindade apenas para beber rum, líquido ingerido pelo deus nas cerimônias; e de um sacrificador que falhou na execução de sacrifícios porque não seguia à risca sua devoção, como assegurou uma deusa diante de uma vasta audiência. Outros casos, ainda, envolveram uma guianense migrada, ausente do país há uma década, cujas percepções quanto ao culto à Kali foram revistas quando detalhes muito íntimos de sua vida foram explicitados por uma manifestação divina; uma viagem de membros de Blairmont ao exterior para realizar um ritual para um trinidadiano que "descobriu" ser necessário honrar seus ancestrais em seu país de origem, após uma divindade que se manifestou em um templo de Kali em Nova Iorque ${ }^{20}$ assim o prescrever; e, finalmente, a deposição de um marlo de seu cargo após uma série de pessoas concluírem que as revelações oraculares emitidas por meio de si não tinham, absolutamente, origem divina, mas antes provinham de sua esposa, que se espreitava entre a audiência para descobrir os problemas de consulentes recém-chegados ao templo, informando seu marido a respeito, como evidenciou outra manifestação divina.

Poderia multiplicar os exemplos aqui, mas me limito a detalhar apenas outros dois, de modo a destacar que 1) no que concerne à manifestação, não está em jogo uma oposição absoluta entre consciência e inconsciência; 2) outros seres, para além de divindades hindus, participam na determinação do que está ocorrendo na vida das pessoas.

Em determinada ocasião o jovem Mohammed compartilhou comigo suas dúvidas quanto ao "nível de consciência" de um marlo, Araf, que manifestava a deusa Mariamma semanalmente. Para Mohammed, alguns acontecimentos lhe pareciam "suspeitos", como as constantes reclamações emitidas pela manifestação de $\mathrm{Araf}^{21}$ a alguns membros do templo, as quais eram em muito semelhantes aos queixumes dirigidos aos mesmos indivíduos pelo sacerdote do local. Ora, Araf era muito próximo ao sacerdote, e em diversos momentos havia "coincidências" entre as revelações emitidas pelas divindades por meio de Araf e as declarações do sacerdote.

\footnotetext{
${ }^{20}$ Estima-se que existam mais guianenses vivendo no exterior do que na própria Guiana. Indo-guianenses migrados fundaram templos em cidades como Miami, Nova Iorque, Fort Lawrence, Toronto, Londres e San Fernando (na ilha de Trinidad). O templo de Nova Iorque mencionado acima é considerado uma "filial" (branch) de Blairmont e efetivamente há muitas trocas entre ambos os templos.

${ }^{21}$ Em Blairmont se diz tanto que uma pessoa manifesta uma divindade, como que uma divindade se manifesta numa pessoa. Embora a manifestação provenha de divindades, é comum que se empreguem sentenças como "a manifestação de Araf", "Araf manifesta Mariamma”, "Mariamma se manifesta em Araf”. Não obstante as variações no emprego de pronomes, considera-se que em última instância quem se manifesta em pessoas são as divindades.
} 
Entretanto, Mohammed não considerava que Araf ${ }^{22}$ fingia a manifestação. $O$ que ocorria é que a manifestação deste último, comparativamente à de outros marlos, "enfraquecia" mais rapidamente, o que explicava os reiterados pedidos da deusa Mariamma, quando nele se manifestava, para intensificar o ritmo de tambores tocados durante os rituais. Assim, explicou didaticamente Mohammed, se progressivamente a consciência individual de Araf "aumentava" à medida que sua manifestação "enfraquecia”, o incremento da sonoridade dos tamborins fazia com que a divindade "voltasse com mais força nele". Adicionalmente, complementou, as prescrições e as revelações de Mariamma por meio de Araf demonstravam-se acertadas, pois muitos consulentes se "curavam" após serem "tratados" por sua manifestação.

Chamo a atenção para a parte final das considerações de Mohammed. Atos, verbais ou não, performados por divindades que se manifestam em humanos embasam outras ações e são constantemente (re)avaliadas à luz de desdobramentos futuros. Assim, mensagens oraculares não remetem apenas a questões de ordem ontológica (o que é) e epistemológicas (o que se sabe e como se sabe), mas também pragmáticas (o que fazer), pois os conhecimentos expressos por meio de divindades implicam manipulações rituais que, uma vez iniciadas, podem não apenas solucionar os problemas das pessoas como fomentar relações que se desdobram no tempo e no espaço.

O segundo caso ao qual farei breve referência, analisado em pormenor alhures (MELLO, 2020), é o de José, um homem de meia-idade que passou a sofrer com os ataques de um espírito holandês (ver nota 10). Em uma visita ao templo de Blairmont, José passou a ser "cuidado" pelo deus Khal Bhairo, cuja manifestação incidia, naquela ocasião, em seu filho, Robert. Subitamente, José começou a manifestar e, incontinenti, foi espancado por Khal Bhairo, que, aos gritos, sugeriu que "outra coisa" se fazia passar por uma divindade hindu. O fato de uma manifestação divina, presente no corpo do filho de José, reprimir o ser corporificado neste último, suscitou algumas piadas. Um membro do templo, de modo muito matreiro, comentou: "Pobre José [...] está sendo espancado pelo filho".

Tal comentário não pôs em xeque a ocorrência da manifestação divina de Khal Bhairo em Robert, apesar da piada, pois revelações oraculares posteriores confirmaram esse veredito: efetivamente, José sofria com um espírito. Dias depois, acompanhei membros de Blairmont à casa de José, onde um "trabalho" foi levado a cabo para aplacar o espírito que, manifestando-se em um marlo, revelou, com um forte sotaque (o espírito não sabia falar inglês apropriadamente), a origem dos problemas de José: as libações feitas a outros espíritos, mas não ao verdadeiro "dono da terra" - no caso, o espírito que emitia essas palavras. José então ofertou alimentos, bebidas alcoólicas, cigarros e um galo branco ao espírito, que se disse "satisfeito" com sua oferta, disposto tanto a deixar José e sua família "em paz" como a controlar os outros espíritos ali residentes. Semanas depois, José recuperou-se prontamente. A revelação oracular inicial, comunicada por meio do corpo de Robert, confirmou-se.

Como dito, realizei nove semanas de devoção para diversas divindades após uma revelação oracular. Deixei de ser mero espectador não apenas por conta dos rituais nos quais me envolvi, mas porque paralelamente o sacerdote do templo de Blairmont estimulou-me a "viver como um devoto para aprender sobre a religião". Assim, tomei parte em diversas atividades: na limpeza de altares e do terreno onde se situa o templo; no preparo de alimentos; na colheita de flores e na 
confecção de guirlandas para as divindades; acompanhando procissões e participando da coleta de itens para festivais; nos preparativos para trabalhos em âmbito doméstico (como aquele acima descrito); assistindo às divindades que se manifestavam, dando-lhes água ${ }^{23}$ e alcançando-lhes instrumentos de cura (notadamente os ramos de folhas de uma árvore considerada sagrada e com poder curativo, a neem); e até mesmo servindo de “intérprete”, isto é, encarregando-me de dar instruções a consulentes sobre como deveriam fazer sua devoção.

Essas relações de proximidade com divindades, especialistas religiosos e consulentes não só me permitiram observar de perto rituais e incrementar meu conhecimento da língua (em especial no que concerne a um amplo léxico de palavras de origem indiana), como me facultaram acompanhar em primeira mão os efeitos desencadeados por revelações oraculares, as conversas íntimas entre divindades e humanos, os rumos de ação prescritos por deuses e deusas, bem como os debates e comentários suscitados pelas mensagens divinas. Desse modo, pude acompanhar os potenciais das revelações oraculares, as articulações daí provenientes e os desdobramentos de relações entre seres com estatuto ontológico distinto.

Igualmente importantes, os comentários, as polêmicas, o caráter sugestivo e ambíguo de algumas declarações e as fofocas conformaram minhas próprias análises acerca do culto à Kali: meus interlocutores e interlocutoras não compartilhavam de visões homogêneas a todo instante, instando-me a refletir sobre questões relativas à verdade em termos menos assertivos. Relações entre pessoas, espíritos e divindades hindus, mesmo quando resolvidas, como no caso de José, eram passíveis de constante reformulação, abriam caminhos cujos percursos não estavam, de antemão, determinados, nem mesmo pela suposta tenacidade de crenças.

\section{Verdade, dúvida e crença: a potência de articulações oraculares}

Durante minha estadia na Guiana, diversos/as guianenses/as perguntaramme, ao tomarem ciência de minha pesquisa, se eu realmente acreditava na possessão das divindades e em seus enunciados verbais. Em larga medida tais indagações refletiam a estigmatização do culto à Kali na Guiana, não raro associado ao diabo, ao maléfico, ao supersticioso, ao atrasado, ao primitivo e ao selvagem. Usualmente, minha resposta era a seguinte: minhas crenças pessoais pouco importavam. O mais relevante era o fato de que algo efetivamente ocorria durante a manifestação: novas relações eram forjadas, outros rituais eram ensejados e debates emergiam a partir da expressão de pontos de vista divinos.

Tais indagações permitem-me abordar duas problemáticas que me parecem centrais: 1) a necessidade de contrabalançar paradigmas fundados na noção de crença; e 2) conceber o culto à Kali não enquanto uma religião já dada, mas antes constituída por práticas que também se moldam por meio da circulação e do entrecruzamento de diversos pontos de vista que, longe de serem aceitos espontaneamente e de se encontrarem estabilizados, se moldam continuamente.

Estudos já clássicos sobre a possessão espiritual exploraram de modo frutífero o modo pelo qual as mensagens transmitidas por espíritos podem estabelecer

${ }_{23}$ Enquanto se manifestam, as divindades derramam incessantemente água, misturada com flores, folhas de neem e pós com propriedades terapêuticas sobre os corpos de marlos. Isso é feito, sobretudo, para "esfriar" os corpos das pessoas, que se aquecem sobremaneira com o poder divino. 
novos canais de comunicação com e entre humanos. Os pontos de vista, os conselhos, as advertências e as revelações expressos em interações redirecionam, mediante redescobertas, extensões e reelaborações retrospectivas, novas camadas de interpretações, estimulando a emergência de novas visões e versões de eventos passados e presentes (BODDY, 1989; LAMBEK, 1981), além de reconfigurar expectativas futuras, não raro trazendo implicações incertas nas relações entre os vivos e os mortos ao longo do tempo (VITEBSKY, 1993).

As perspectivas de Boddy e Lambek, formuladas no apogeu de paradigmas interpretativos em antropologia, podem ser complementadas por análises mais atentas aos modos pelos quais atos verbais concorrem, ou não, para a consolidação de interpretações permeadas pelo entrecruzamento de pontos de vista humanos e não-humanos. Como demonstrou Irvine (1982), a inteligibilidade de canais de comunicação estabelecidos pela possessão espiritual pode ser clarificada de diversos modos, mas além de a participação de uma audiência mais ampla ser fundamental, nem sempre as dúvidas e controvérsias se encerram, na medida em que rituais podem fornecer mais elementos para deliberação, em vez de simplesmente reforçarem visões comuns.

Para meus interlocutores e interlocutoras, as revelações oraculares atestam a potência das divindades, seres capazes de evidenciar a "verdade". Ainda que devotos e devotas atestem a necessidade de se ter "fé" nas divindades, em relações concretas não se está diante da tenacidade de crenças ou da adesão imediata ao conteúdo das mensagens veiculadas pelas divindades. Em um recente estudo sobre a bruxaria na Indonésia, Nils Bubandt (2014) nota que a dúvida ocupa um lugar crucial e estranho na antropologia, pois dúvidas e ambivalências são tratadas como aspectos temporários, passíveis de resolução, de crenças e suas funções sociais derivadas.

A persistência desse "paradigma explanatório”, para utilizar o vocabulário do autor, provém desde Evans-Pritchard (1980 [1937]), cuja clássica monografia não ignora contradições, ambivalências, o papel de hierarquias internas no próprio conteúdo das questões formuladas aos oráculos e situações concretas por meio das quais revelações oraculares se articulam às explicações sobre certos acontecimentos, como infortúnios. Assim, e como notou Tambiah (2013), em sua época Evans-Pritchard notou as limitações de descrições centradas exclusivamente em crenças místicas que ignoravam o comportamento empírico das pessoas no cotidiano, como se elas habitassem o universo mental de crenças místicas o tempo todo. Dito de outro modo, crenças não são resultados de tradições impensadas que ignoram experiências que porventura as contradigam (Cf. LIENHARDT, 1964).

Não obstante, e sem ignorar o tom de denúncia de diversos trechos de $\mathrm{Bru}$ xaria, Magia e Oráculos (ver GIUMBELLI, 2011), e o emprego de estratégias de pesquisa um tanto problemáticas - notadamente o incitamento de rivalidades entre adivinhos para se extrair informações de outro modo inacessíveis -, ao cabo Evans-Pritchard lança mão de uma "explicação circular" (Cf. HOLBRAAD, 2012), pois a confiabilidade nos oráculos é reforçada por elaborações secundárias da crença que acabam por reforçar a crença na bruxaria, mesmo que dúvidas emerjam constantemente. Para Holbraad, caberia descrever mais atentamente formas diferenciadas de se engajar com a verdade - como no caso dos oráculos de Ifá em Cuba -, comparando-as com noções de verdade na antropologia. Ao propor uma antropologia recursiva, Holbraad - cujas indagações repousam fundamentalmente no plano conceitual - desestabiliza, por meio da comparação, a força de 
concepções antropológicas representacionalistas, seguindo a motilidade da verdade em cenários nos quais a noção de caminho aponta menos para traçados lineares e mais para a potencialidade, e a multiplicidade, de caminhos que sempre abrem novos caminhos - e "fecham" outros tantos, podemos acrescentar, embora o porvir possa reabrir caminhos já trilhados de outras maneiras. Assim, não se trata apenas de fechamento e abertura: caminhos interligam seres humanos e não-humanos de modos variados, tornam-se emaranhados justamente porque não resultam apenas de pronunciamentos oraculares, afinal sempre há outras fontes de experiência na vida das pessoas.

Em consonância à proposta de Bubandt (que, se comparada a de Holbraad, é mais fundada na etnografia), sugiro que dúvidas podem ser tratadas como uma dimensão do caráter altamente reflexivo dos engajamentos das pessoas com revelações oraculares e divindades, afinal eventuais desconfianças não necessariamente são o reverso oposto da confiança (CAREY, 2017). Nesse sentido, minha narrativa etnográfica buscou destacar o caráter mutável e dinâmico de relações marcadas pela presença de entes espirituais no cotidiano dos humanos, para além da esfera religiosa. Mensagens transmitidas por divindades - e também por espíritos - não se encerram nos momentos de sua enunciação, pois são marcadas por uma série de "validações empíricas" (Cf. PELKSMAN, 2018) acerca do próprio conteúdo dessas mensagens. O modo pelo qual tais validações se tornam vereditos (ou melhor, versões estabilizadas sobre certos acontecimentos e seus desdobramentos) são repletas de evidências fragmentárias, ambivalências, dúvidas, hesitações e testes de hipóteses. Assim, o "senso do inesperado" (Cf. CARDOSO, 2007; 2014) da agência de entes espirituais torna a dúvida um elemento central das interações entre espíritos, divindades e humanos. Dúvidas que não necessitam ser abordadas à luz de suas funções sociais, nem enquanto aspectos transitórios de crenças.

Metodológica e teoricamente, isso implica indagar, baseado nas sugestões de Romberg (2014), em que medida dúvidas sobre a veracidade de eventos de possessão espiritual são formuladas sem que a autenticidade de mensagens transmitidas por espíritos e divindades sejam, necessariamente, totalmente refutadas. Assim, é fundamental perguntar quem está sendo testado: médiuns, entes espirituais, ou ambos? Do mesmo modo, cabe atentar que diferentes participantes de rituais podem veicular distintas interpretações de eventos religiosos, autenticando diferencialmente a veracidade de experiências religiosas (WIRTZ, 2007).

Semelhantemente ao caso de Cuba descrito por Panagiotopoulos, no caso do culto à Kali não se trata somente da tenacidade de crenças, ditas religiosas. Se é indispensável ter fé nas divindades, o campo de possibilidades aberto por revelações oraculares demonstra que a permeabilidade de humanos aos pontos de vista de não-humanos (ISHII, 2012) envolve distintas ordens de participação (PINACABRAL, 2018; 2019) de pessoas não-humanas na vida dos humanos. Se a noção moderna de crença se assenta em valores liberais que a concebem enquanto fenômeno interno, privado e essencialmente mental (Cf. ASAD, 1993), cumpre notar que diversos agentes participam, de modos variados, da formação de "verdades" acerca de fenômenos atravessados pela agência espiritual.

Os encontros suscitados pela pesquisa de campo não estão apartados de artifícios narrativos, discursivos e estilísticos que redimensionam fatos do campo à luz de artefatos conceituais que portam consigo histórias específicas. Neste texto busquei demonstrar como revelações oraculares incidiram não só sobre a dinâmica de minha pesquisa de campo ou sobre experiências subjetivas do pesquisador. Mensagens oraculares concorrem para a criação e recriação de relações entre 
devotos e devotas de Kali, promovendo a circulação de pontos de vista múltiplos, pontos de vista esses que trazem consigo potencialidades diversas, fomentando manipulações rituais e lançando possibilidades nas trajetórias de vida de pessoas. Revelações oraculares apontam não apenas para o que é ou o que foi, mas para o que pode vir a ser.

Em resposta a alguns interlocutores mais próximos, interessados em saber como, e por que, afinal, eu viajara a Guiana e, mais especificamente, como eu me encontrara com Kali, narrei parte do meu trajeto enquanto estudante no Brasil, destacando como decisões tomadas anos atrás, eventos inesperados e sugestões até então inimaginadas fizeram-me chegar onde cheguei. Não me parece à toa que pelo menos seis interlocutores mais próximos - Bayo, Arjune, Omar, Kesho, Reshme e Nadya - tenham reagido de forma muito semelhante: ouviram a narrativa com atenção, sorriram com assentimento, e declararam: "A Mother (Kali) o trouxe aqui".

Essa declaração, aparentemente simples, parece-me tão singela como potente. Singela e potente porque Kali, a Divindade Suprema, "sabe de tudo"; ela "vê tudo", como se diz. A Mother vê tudo porque os seres humanos são, por natureza, limitados; seus raios de visão, e suas percepções, são, por assim dizer, mais confinados, comparativamente ao poder visual das divindades. Os olhares retrospectivos sobre eventos passados trazem consigo o potencial de reavaliar caminhos já trilhados, expandindo seus horizontes. Talvez a verdade se constitua pela movimentação contínua de antevisões que, estabilizadas por narrativas, permitem vislumbrar relances de traços e vestígios de percursos que em realidade nunca se encerraram, pois continuam a acontecer. Oráculos articulam potencialidades e itinerários em permanente expansão. Nos encontros etnográficos, explicações antropológicas são constantemente postas à prova por prognósticos que desestabilizam vaticínios, pois prenunciam possibilidades.

Recebido em 3 de dezembro de 2019.

Aceito em 8 de janeiro de 2020.

\section{Referências}

ASAD, Talal. Genealogies of religion. Discipline and reasons of power in Christianity. Baltimore: John Hopkins University Press, 1993.

BAHADUR, Gaiutra. Coolie woman. The odyssey of indenture. Chicago: The University of Chicago Press, 2013.

BICKERTON, Derek. Dynamics of a creole system. Cambridge: Cambridge University Press, 1975. 
BODDY, Janice. Wombs and spirits. Women, men, and the Zar cult in Northern Sudan. Madison: The University of Wisconsin Press, 1989.

BUBANDT, Nils. The empty seashell. Witchcraft and doubt on an Indonesian island. Ithaca: Cornell University Press, 2013.

CARDOSO, Vânia. Narrar o mundo: estórias do "povo da rua" e a narração do imprevisível. Mana - Estudos de Antropologia Social, 13 (2): 317-375, 2007.

CARDOSO, Vânia. "Spirits and stories in the crossroads". In: BLANES, Ruy \& ESPÍRITO SANTO, Diana (eds.). The Social Life of Spirits. Chicago: The University of Chicago Press, 2014. pp. 93-107.

CAREY, Matthew. Mistrust: an ethnographic theory. Chicago: The University of Chicago Press/HAU Books, 2017.

CONNOLY, Jonathan. Indentured labour migration and the meaning of emancipation. Past and Present, 38 (1): 85-119, 2018.

EVANS-PRITCHARD, Edward. Bruxaria, oráculos e magia entre os Azande. Rio de Janeiro: Zahar, 1980 [1937].

IRVINE, Judith. "The creation of identity in spirit mediumship and possession". In: PARKIN, David (ed.). Semantic Anthropology. London: Academic Press Inc. 1982, pp. 241-260.

GIUMBELLI, Emerson. A noção de crença e suas implicações para a modernidade. Horizontes Antropológicos, 17 (35): 327-356, 2011.

HINTZEN, Percy. The costs of regime survival. Racial mobilization, elite domination and control of the state in Guyana and Trinidad. Cambridge: Cambridge University Press, 1989.

HOLBRAAD, Martin. Truth in the motion: the recursive anthropology of Cuban divination. Chicago: The University of Chicago Press, 2012.

ISHII, Miho. Playing with perspectives: spirit possession, mimesis, and permeability among the buuta ritual in South India”. Journal of the Royal Anthropological Institute, 19: 795-821, 2012.

JOHNSON, Paul. Scholars possessed! On writing Africana religions with the left hand. Journal of Africana Religions, 4 (2): 154-185, 2016.

KLOB, Sinah. Fabric of Indianness. The exchange of clothes in transnational Guyanese Hindu communities. New York: Palgrave McMillan, 2016.

KLOß, Sinah. Sexual(ized) harassment and ethnographical fieldwork: a silenced aspect of social research. Ethnography, 18 (3): 396-414, 2017.

LAMBEK, Michael. Human spirits: a cultural account of trance in Mayotte. Cambridge: Cambridge University Press, 1981.

LIENHARDT, Godfrey. Social anthropology. London: Oxford University Press, 1964 .

LOOK LAI, Walter. Indentured labour, Caribbean sugar. Chinese and Indian migrants to the British West Indies, 1838-1918. Baltimore: John Hopkins University Press, 1993. 
MELLO, Marcelo Moura. Devoções manifestas. Religião, pureza e cura em um templo hindu da deusa Kali (Berbice, Guiana). Tese (Doutorado em Antropologia Social). Rio de Janeiro: Programa de Pós-Graduação em Antropologia Social, Museu Nacional, Universidade Federal do Rio de Janeiro, 2014.

MELLO, Marcelo Moura. Mimesis, dúvida e poder: espíritos de colonizadores e divindades hindus na Guiana. Horizontes Antropológicos, 26 (56): 57-86, 2020.

PANAGIOTOPOULOS, Anastasios. Food-for-words: sacrificial counterpoint and oracular articulacy in Cuba. Hau - Journal of Ethnographical Theory, 8 (3): 474487, 2018.

PELKSMAN, Mathijs. "Doubt, suspicion, mistrust...semantic approximations”. In: MÜHLFRIED, Florian. (ed.) Mistrust: ethnographic approximations. Bielefeld: Transcript, 2018, pp. 169-178.

PINA-CABRAL, João de. Modes of participation. Anthropological Theory, 18 (4): 435-455, 2018.

PINA-CABRAL, João de. My mother, or father: person, metaperson, and transcendence in ethnographical theory. Journal of the Royal Anthropological Institute, 25: 3030-323, 2019.

PIRES, Rogério; STRANGE, Stuart; MELLO, Marcelo Moura. The Bakru speaks: Money-making demons and racial stereotypes in Guyana and Suriname. New West Indian Guide, 92 (1-2): 1-34, 2018.

RABELO, Miriam. Enredos, feituras e modos de cuidado. Dimensões da vida e da convivência no candomblé. Salvador: EDUFBA, 2014.

RICKFORD, John. Dimensions of a creole continuum. History, texts and linguistic analysis of Guyanese creole. Stanford: Stanford University Press, 1987.

ROMBERG, Raquel. "Mimetic corporality, discourse and indeterminacy in spirit possession". In: JOHNSON, Paul (ed.). Spirited things. The work of "possession" in Afro-Atlantic religions. Chicago: The University of Chicago Press, 2014. pp. 225-256.

SIDNELL, Jack. Talk and practical epistemology. The social life of knowledge in a Caribbean community. Amsterdam/Philadelphia: John Benjamins Publishing Company, 2005.

SMITH, Raymond T. "Living in the gun mouth": race, class and political violence in Guyana. New West Indian Guide, 69 (3-4): 223-252, 1995.

STOLLER, Paul. Sensuous scholarship. Philadelphia: University of Pennsylvania Press.

TAMBIAH, Stanley. Múltiplos ordenamentos da realidade: o debate iniciado por Lévy-Bruhl. Cadernos de Campo, 22: 193-220, 2014.

TAUSSIG, Michael. What color is the sacred? Chicago: The University of Chicago Press, 2009.

TROTZ, Alissa. Between despair and hope: women and violence in contemporary Guyana. Small Axe, 8 (1): 1-20, 2004.

VITEBSKYY, Piers. Dialogues with the dead. The discussion of mortality among the Sora of Eastern India. Cambridge: Cambridge University Press, 1993. 
WILLIAMS, Brackette. Dutchman ghosts and the history mystery: ritual, colonizer, and colonized interpretations of the 1763 Berbice slave rebellion”. Journal of Historical Sociology, 3 (2): 133-165, 1990.

WILLIAMS, Brackette. Stains on my name, war in my veins. Guyana and the politics of culture struggle. Durham: Duke University Press, 1991.

WIRTZ, Kristina. Ritual, discourse and community in Cuban Santería: speaking a sacred world. Gainesville: University Press of Florida, 2017. 